\title{
ESPAÇOS LIMINARES E VITALIDADE URBANA: FOTO-ENSAIO SOBRE A APROPRIAÇÃO DO ESPAÇO PÚBLICO EM TRÊS BAIRROS CRIATIVOS.
}

\author{
Pedro Costa e Ricardo Lopes \\ DINÂMIA'CET-IUL ${ }^{1}$
}

\begin{abstract}
Neste foto-ensaio efectua-se uma abordagem personalizada às lógicas de apropriação e (re)construção do espaço público no contex to de 3 bairros criativos em outras tantas cidades distintas: o Bairro Alto, em Lisboa, a Gràcia, em Barcelona, e a Vila Madalena, em São Paulo. Através da análise das imagens recolbidas de forma sistemática nestes 3 bairros, com base num conjunto de dimensões de análise pré-estabelecidas, equaciona-se a vitalidade destes espaços a partir da sua liminaridade e dos conflitos que nele se geram quotidianamente, ao nivel do espaço físico, das vivências de que ele é alvo e da sua construção simbólica. A análise aqui efectuada insere-se no quadro mais amplo da investigação desenvolvida pelos autores no âmbito do projecto CreatCity, no qual se estudam as raizes, as formas e a governança das "dinâmicas criativas" em diversos contextos urbanos nestas 3 cidades.
\end{abstract}

Palavras-Chave: espaço público, criatividade, vitalidade urbana, investigação visual, fotografia, bairros culturais

\section{INTRODUÇÃo}

Certos bairros, um pouco por todo o mundo, têm a capacidade de se afirmar como centros da criatividade e da vida cultural das cidades onde se encontram (Scott, 2000; Costa et al, 2008). Estes "bairros criativos" são zonas onde fervilha a oferta cultural e artística, da mais "convencional” à mais "alternativa", mas são também espaços de encontro e sociabilidade, de grande vitalidade urbana, onde a arte e a cultura estão normalmente associadas à boémia e à vida nocturna (O’Connor e Wynne, 1996; Scott, 2000; Costa, 2007; Cooke e Lazzeretti,

1 Centro de Estudos sobre a Mudança Socioeconómica e o Território (ISCTE-IUL). Os autores agradecem a Cristina Latoeira, co-autora do artigo de base que foi o ponto de partida para este foto-ensaio (Costa et al, 2010), bem como aos restantes colegas envolvidos na recolha fotográfica nestes três bairros (Samuel Dias e Ana Roldão). Contatos: pedro.costa@iscte.pt, ricardovenanciolopes@gmail.com 
2009). São espaços liminares, de múltiplas codificações e sentidos, onde coexistem pessoas e actividades muito diversas (Arantes, 1997); onde tem lugar a criação e a produção cultural, mas onde muitas vezes esta vai dando crescentemente lugar apenas a um consumo esteticizado e simbolicamente muito marcado (O’Connor e Wynne, 1996; Zukin, 1995; Fortuna, 1997), com o avanço dos processos de gentrificação. Muitos deles, mesmo nessa situação, mantêm no entanto a capacidade de funcionar como nós centrais nos processos de convivialidade e de sociabilidade que são fulcrais na criação de reputação e legitimação nas actividades culturais (Becker, 1982; Di, Maggio, 1987; Caves, 2002; Borges e Costa, 2012; Costa, 2012). São zonas onde a transgressão e a capacidade de explorar novos caminhos, características essenciais à criação artística mais alternativa e inovadora, são mais fáceis; espaços onde o controlo social é menos forte e portanto a expressão da diferença e a assunção dos riscos se encontram bem mais facilitadas.

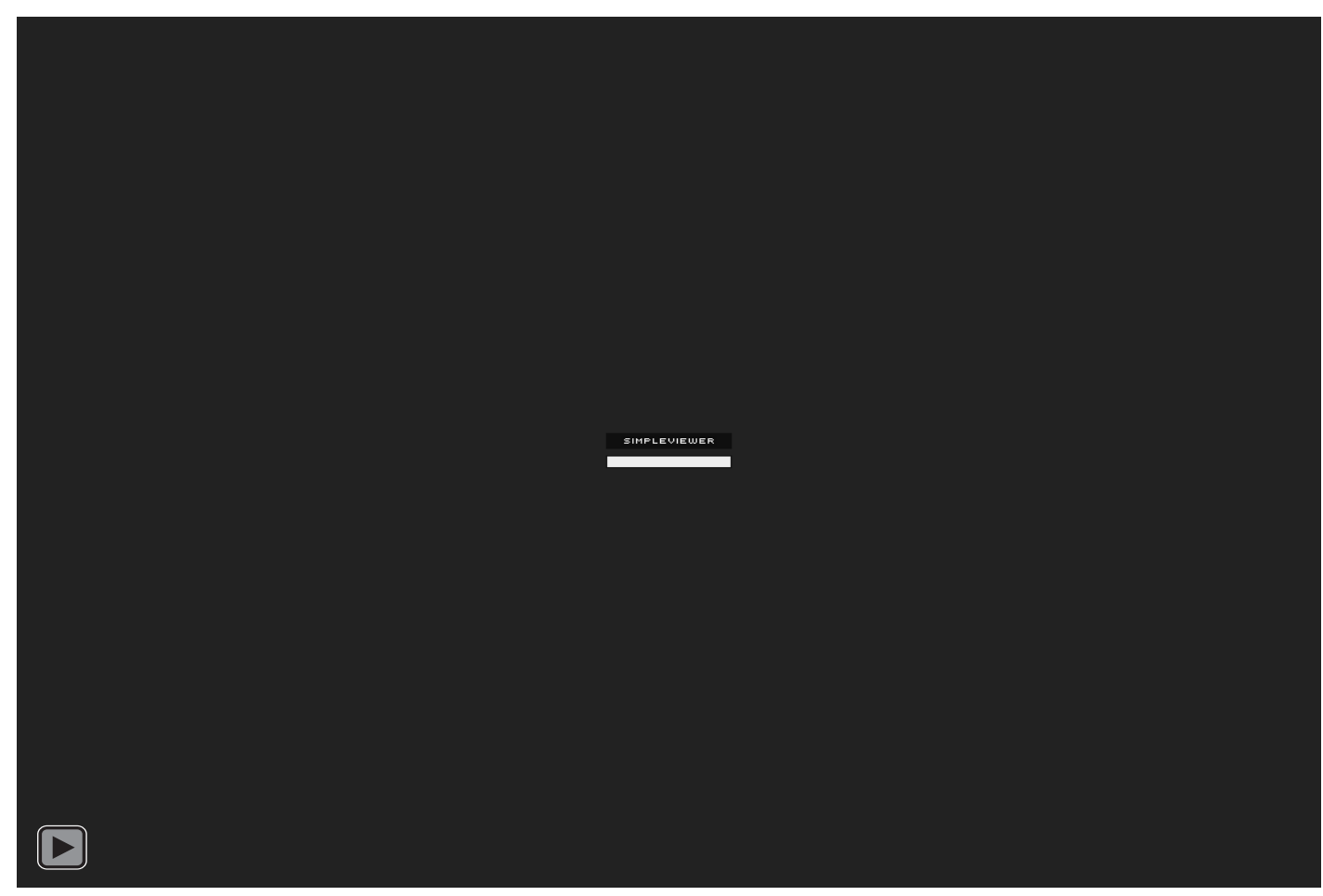

Mas são também zonas onde os conflitos urbanos se manifestam com muita frequência, onde quotidianos distintos e contrastantes se cruzam, não raras vezes com alguma fricção. $\mathrm{E}$ espaços sujeitos a processos de gentrificação e à especulação imobiliária, onde muitas vezes as actividades culturais e artísticas que nele se afirmaram, substituindo gradualmente os moradores e actividades mais tradicionais, são elas próprias rapidamente postas em causa, sendo substituídas por outras actividades e outros estratos sociais, com mais capacidade para viver nestes espaços crescentemente valorizados, seja economicamente, seja nas representações sociais das populações (Costa, 2007).

Os espaços públicos (e os espaços privados pertencentes à esfera pública) são aqui uma arena privilegiada de todas estas dinâmicas e têm um papel fundamental na vivência dessas zonas (cf. Costa et al, 2010). Territórios de transgressão e liminaridade, de afirmação simbólica individual e de construção de identidades colectivas, mas também territórios naturalmente muito marcados pelas vivências quotidianas das populações mais tradicionais. Espaços de tensão e de conflito, de sociabilidades e de encontros, de coexistências nem sempre pacíficas, 
onde a apropriação, física e simbólica, do lugar se faz de formas muito diferenciadas, e onde várias camadas de leitura e de codificação se vão sobrepondo e coexistindo, à luz dos diferentes olhares dos múltiplos utilizadores e produtores desses territórios. Espaços públicos cada vez mais fluidos, em que cada vez mais se tornam difusas as dicotomias entre noite e dia, trabalho e prazer, vida pública e vida privada, tradicional e (pós)moderno (cf O’Connor e Wynne, 1996; Costa, 2007).

Foram exactamente estes espaços públicos e as múltiplas formas como são apropriados, marcados e experienciados pelas diversas camadas sociais que os vivem e usam quotidianamente, que foram alvo da abordagem fotográfica que serve de base a este foto-ensaio. No âmbito de um projecto de investigação mais amplo, de carácter interdisciplinar, sobre as raízes da criatividade na cidade e as formas de governança que podem ajudar à sua sustentabilidade (o projecto CreatCity ${ }^{2}$ ), 5 fotógrafos/investigadores percorreram o Bairro Alto em Lisboa, o Barrio da Gràcia, em Barcelona e a Vila Madalena, em São Paulo, em busca dessas criatividade e vitalidade urbanas, procurando os seus sinais na apropriação do espaço público, nas manifestações culturais e criativas e nos conflitos, nas vivências quotidianas e nas marcas estruturais de mudança nesses bairros.

Libertos de grandes espartilhos estéticos ou formais, cada um dos 5 fotógrafos (Ana Roldão, Cristina Latoeira, Pedro Costa, Ricardo Lopes e Samuel Dias) procurou dar a sua leitura pessoal sobre a vivência e a transformação destes bairros a partir dos seus espaços públicos, e sobre como eles serão ou não (ainda?) a expressão da criatividade artística e da vitalidade urbana em cada uma destas três metrópoles.

Neste foto-ensaio os autores propõem, através de uma breve leitura destas imagens, também ela personalizada, uma tentativa de síntese das viagens possíveis por essa recolha, fazendo uma (re)interpretação de uma base de imagens que possibilita, para um conjunto de dimensões de análise e temas concretos de observação desse objecto empírico, uma visão plural e abrangente de 3 bairros que sem dúvida apresentam uma vitalidade e uma abertura à criatividade exemplares em cada uma das respectivas metrópoles. Uma análise mais descritiva e extensiva desta realidade, bem como das suas implicações em termos das lógicas de apropriação do espaço nos 3 bairros e dos conflitos de uso subjacentes pode ser consultada em Costa et al., 2010. Um aprofundamento da grelha teórica e conceptual que serviu de base à pesquisa, bem como das estratégias metodológicas que foram prosseguidas no programa de investigação em que esta análise se enquadra poderão ser consultadas em Costa, 2013.

\section{Aspectos Metodológicos: A ReCOLHA DE IMAgens nOS 3 baiRRos}

A análise do espaço público que foi efectuada partiu de uma abordagem fotográfica comparativa às realidades dos três bairros, tentando seguir um conjunto pré-sistematizado de critérios. No âmbito de uma linha de pesquisa específica dentro do projecto CreatCity ${ }^{3}$,

2 Para mais informação sobre o projecto (CreatCity - A governance culture for the creative city: urban vitality and international networks - PTDC/AUR/65885/2006) consulte-se o site respectivo: http://creatcity.dinamia. iscte.pt/, bem como Costa, 2013.

3 O seu work-package $\mathrm{n}^{\circ}$ 4, cujo objetivo em concreto era analisar a relação das dinâmicas criativas encontradas com a morfologia do espaço, e o seu contributo para a vitalidade urbana, com uma análise centrada nestes 3 bairros 
procedeu-se ao levantamento fotográfico dos três bairros culturais em causa, recolha essa que decorreu a par de outros levantamentos e de outros tipos de abordagens complementares que visavam a recolha sistemática de informação empírica, tanto qualitativa como quantitativa, sobre os mesmos locais visando corresponder aos objectivos mais amplos deste work-package ${ }^{4}$. Com base no vasto conjunto de imagens recolhidas no âmbito desse levantamento fotográfico procurava-se em particular entender as dinâmicas criativas e de apropriação do espaço público num conjunto de 15 domínios temáticos, agrupados em torno de algumas dimensões de análise.

O levantamento fotográfico obedeceu a um conjunto de regras e pressupunha determinados objectivos específicos, para uma cobertura o mais completa e comparável possível das dinâmicas dos bairros. Para cada bairro, foram seleccionadas seis ruas ou praças com diferentes utilizações e usos, que representassem as diferentes dinâmicas pré-identificadas no local. Durante dois dias específicos da semana (quinta e sexta-feira), e em três momentos diferentes (manhã, tarde e noite $)^{5}$ foram recolhidas as imagens nos seis pontos escolhidos em cada bairro, pelos cinco elementos da equipa do projecto envolvidos nesta tarefa.

Foi objectivo deste trabalho específico fazer um levantamento que fosse baseado na interpretação e leitura que cada um dos elementos da equipa, com origens disciplinares diversas ${ }^{6}$, assumia sobre o espaço público. Partindo do conjunto de dimensões de análise comuns, pré-selecionadas, e de uma reflexão conceptual conjunta sobre o espaço público e suas lógicas de apropriação nos bairros criativos (assumindo aqui a lógica Beckeriana de promover o imprescindível fio condutor entre análise teórica e conceptual prévia à recolha da imagem fotográfica - Ferro, 2005), cada elemento procurou expressar a sua visão sobre cada bairro e ler a apropriação do espaço de cada bairro, à luz dessa grelha de análise. A partir das perspectivas mobilizadas por cada fotógrafo, seria necessário apreender pela posterior leitura, discussão e análise das fotografias a forma como é feita a apropriação dos espaços públicos do bairro, elaborando conjuntamente uma leitura de síntese de como este condiciona as práticas sociais, económicas e culturais que nele se desenrolam.

Assumimos aqui portanto uma perspectiva em que a fotografia é vista como um meio que nos permite uma análise que tem naturalmente de equilibrar realidade e representação, e onde a construção social pela via dos intervenientes não é despicienda. Como refere Silva (2007), partindo das ideias de Barthes ${ }^{7}$, a imagem combina necessariamente um cunho conotativo (sendo portadora de uma codificação referente a um determinado saber cultural e a um determinado sistema simbólico) com um cunho denotativo (tendo um certo poder de

que foram assumidos como estudos de caso nas 3 metrópoles envolvidas na pesquisa (veja-se a este propósito, Costa et al, 2010, Balula, 2010).

4 Note-se, que tal como Ferro (2005), entendemos as imagens do fenómeno social recolhidas pela fotografia como um complemento (e não uma substituição) à voz dos seus protagonistas, aferida por outros meios. A máquina fotográfica, é apenas mais um instrumento da análise social (nesta pesquisa complementado por diversos outros - levantamento urbanístico, análise de dados estastísticos, análise bibliográfica e documental, entrevistas, etc), não obstante ser apenas o fruto específico dessa análise que nos foca o olhar neste artigo em concreto.

$5 \quad$ Face às dinâmicas específicas destes bairros culturais, foram escolhidos dias e momentos similares nas 3 cidades, com 3 slots horários (10:00-12:00; 17:00-19:00; 23:00-01:00) que permitissem captar a diversidade de dinâmicas e utilizadores do bairro).

6 Geografia, Economia, Planeamento Regional e Urbano e Arquitectura.

7 Veja-se a este propósito, Barthes, 2006. 
representação ou "recorte" do real). Nesse sentido, as representações sociais da imagem têm uma relação dialética entre realidade e sistema de interpretação:

$[\mathrm{N}]$ a produção documental videográfica e fotográfica de uma determinada cultura, é possível enxergarmos os ícones simbólicos de significação de poder, reconhecimento, representações sociais e ideologias que demarcam o conjunto simbólico das identidades em questão, em um determinado espaço social. A autoreferência da imagem é recheada de significantes identitários que equilibram realidade e representação que são, ao mesmo tempo, estética e documentalmente relevantes" (Silva, 2007, pp. 609-10).

Para tal, tendo sempre presente a vertente "documental" sobre a realidade que cada um dos investigadores-fotógrafos quisesse transmitir, foi necessário "ler" a realidade através de um conjunto de aspectos caracterizadores de cada um destes bairros e das suas vivências, desde a diversidade dos seus utilizadores e frequentadores (nos seus diversos tempos e espaços), à multiplicidade dos espaços existentes (morfologia, características físicas, materiais, mobiliário urbano, etc.), à pluralidade de usos, vivências e apropriações que neles se reconhecessem (nas formas de utilização, de codificação, etc.), aos conflitos de uso e problemas associados às externalidades nele ocorridas, e ainda à variedade das expressões simbólicas e das representações, individuais e colectivas, associadas às práticas sociais existentes nestes espaços. Na prática, a nossa estratégia metodológica ancorou-se assim no procedimento de "obedecer à lógica da reflexão constante acerca do objecto de estudo e das condições (teóricas e sociais) da investigação" (Ferro, 2005, p.392).

Partindo de um quadro conceptual que olhava para estes espaços numa tripla perspectiva (cruzando morfologia, formas de apropriação e formas de governança) (cf. Costa el al, 2010, Costa, 2013), assumiu-se um conjunto de variáveis-chave para a análise da vitalidade urbana destas zonas, procurando abarcar aspectos tão diversos como a diversidade funcional e social, as acessibilidades, as identidades e o capital social, a "qualidade" do local ou a criatividade local.

Neste contexto, operacionalizaram-se três grandes dimensões para a análise dos espaços públicos. Estas três grandes dimensões foram decompostas em temas, a partir dos quais a recolha fotográfica foi conduzida e a análise foi posteriormente concretizada, recorrendo à leitura, discussão comparativa e interpretação conjunta das imagens recolhidas nos diversos casos de estudo:

- O espaço físico - a forma como o espaço natural e construído condiciona as actividades e funções que nele se desenvolvem

- As materialidades

- O mobiliário urbano

- Os espaços verdes

- A "luz"

- A vivência do espaço - a forma como é vivido, e apropriado pelos seus diversos utilizadores (moradores, trabalhadores, turistas, etc.) e os conflitos que isso gera

- A diversidade funcional do bairro

- A diversidade social do bairro

- "Habitar" o bairro

- "Circular" no bairro

- O "viver" o bairro 
- A dimensão simbólica - como é percepcionado e representado e como condiciona e diversifica as múltiplas apropriações (e acessibilidades simbólicas e culturais)

- Os signos e os símbolos

- As características identitárias do bairro

- Os espaços de inclusão e exclusão (simbólica/cultural)

A estas 3 dimensões acrescentou-se ainda uma quarta dimensão de análise que focaliza os temas transversais aos restantes, que consubstanciam as próprias dinâmicas dos bairros nos seus diversos tempos e espaços, ou seja as suas múltiplas - mas coincidentes entre bairros temporalidades e espacialidades:

- Dimensões transversais

- $\quad$ os diferentes tempos / ritmos do bairro

- os diferentes "espaços" do bairro

\section{OS DIFERENTES TEMPOS E RITMOS DOS BAIRROS: FOTO-ENSAIO}

É a partir destas 4 dimensões e destas 15 cambiantes temáticas que propomos esta digressão pelas imagens selecionadas para consubstanciarem este foto-ensaio. $\mathrm{Na}$ impossibilidade de uma visão mais abrangente no contexto deste foto-ensaio, apresenta-se a título ilustrativo, uma selecção de imagens apenas referentes a um dos temas: "Os diferentes ritmos/tempos do bairro" (no âmbito das "Dimensões transversais"). Esta selecção deveu-se a ser o tema que, face à perspectiva da liminariedade sob a qual olhamos para os 3 bairros neste ensaio, representa de uma forma mais transversal as diversas dimensões analisadas e a multiplicidade de situações e utilizadores percepcionados pela leitura fotográfica decorrente da recolha de imagens ao longo dos três momentos diários, nos diferentes locais dos bairros. Estas imagens permitem-nos, por um lado, olhar de forma sintética para a vitalidade destes 3 bairros, a partir dos múltiplos espaços de liminariedade co-existentes que eles proporcionam aos seus vários utilizadores "paralelos" e, por outro, dar conta das dinâmicas que neles vão evoluindo ao longo do dia, as quais apresentam regularidades marcantes nas "temporalidades" entre os 3 casos.

A selecção destas imagens foi efectuada com base num conjunto de critérios que procurou representar a grande diversidade encontrada nestes bairros, assegurando em termos genéricos sensivelmente o mesmo número de fotografias para cada um dos bairros, e para cada um destes, a selecção de imagens de diferentes ruas e horas do dia, procurando assim evidenciar a multiplicidade de dinâmicas encontradas. A sequência das imagens segue a ordem cronológica dos ritmos dos bairros ao longo do dia (manhã, tarde, noite), iniciando-se a exibição com fotografias do período da manhã, marcadas por um ritmo calmo, e pelos moradores a realizarem as suas actividades diárias e cuidar do espaço público adjacente às suas habitações; em seguida apresentam-se imagens do período do final da tarde, altura em que começa a coexistir uma maior heterogeneidade de utilizadores associada à transformação comercial que se assiste nos bairros e que contribui para o mix de acontecimentos que ocorrem nos espaços públicos; no período nocturno a sequência de fotos é marcada pelo contraste entre o ritmo "agitado" das 
ruas de maior animação nocturna e as calmas ruas residênciais. A interpolação de fotos dos três bairros em cada um destes períodos, promovendo o diálogo entre as imagens, visa salientar a universalidade das dinâmicas encontradas nos 3 contextos.

Para o acesso a uma visão exaustiva das 15 dimensões de análise consideradas consulte-se Costa et al, 2010.

\section{Nota CONCLUSIVA}

Procurou-se com este foto-ensaio possibilitar uma leitura acerca dos espaços públicos existentes nos 3 bairros criativos em análise neste projecto e das múltiplas formas como são apropriados, marcados e experienciados pelas diversas camadas de utilizadores que os vivem e usam quotidianamente. Os três bairros, não obstante as suas naturais múltiplas diversidades e especificidades, a nível morfológico, urbanístico, funcional e institucional, apresentam similaridades e regularidades que importa considerar e analisar em profundidade quando se pensa e se actua sobre os "espaços urbanos criativos". Tendo plena consciência que estes não se criam do nada nem no vazio, tal como mostra Hospers (2003), importa perceber em que factores assenta a génese e a sustentabilidade das dinâmicas verificadas em cada um destes espaços, e como se gerem quotidianamente os conflitos inevitavelmente subjacentes aos múltiplos interesses que naturalmente se jogam e expressam nestes locais (cf Costa,2013). As imagens, aqui apresentadas, utilizadas em complementaridade com diversas outras metodologias de recolha e tratamento de informação desenvolvidas no âmbito deste projecto, permitem-nos aprofundar o debate desta questão. Com todas as suas fragilidades (decorrentes de uma abordagem fotográfica pessoal e naturalmente interpretativa da realidade tal como é abarcada por cada um dos investigadores), mas também com toda a sua "verdade" (por toda a leitura que proporcionam das dinâmicas reais que confrontaram e foram surpreendendo esses mesmos investigadores), são um precioso instrumento para esta reflexão.

\section{REFERÊNCIAS}

Arantes, A. 1997. "A guerra dos lugares: fronteiras simbólicas e liminaridade no espaço urbano de São Paulo". Pp. 259-270 in Cidade, Cultura e Globalização - Ensaios de Sociologia. Fortuna, C. (org.). Oeiras: Celta.

Balula, L. 2010. "Espaço público e criatividade urbana: A dinâmica dos lugares em três bairros culturais”. Cidades, Comunidades e Territórios, no20/21, Dezembro 2010: 43-58.

Barthes, R. 2006[1980]. A Câmara Clara. Lisboa: Edições70.

Becker, H. S. 1982. Art Worlds. Berkeley / Los Angeles / London: University of California Press. Borges, V. e Costa, P. (org.). 2012. Criatividade e instituiçóes: Novos desafios à vida dos artistas e profissionais da cultura. Lisboa: Imprensa de Ciências Sociais.

Caves, R. 2002. Creative Industries: Contracts between Art and Commerce. Cambridge / London: Harvard University Press.

Campos, R., A. Mubi Brighenti, L. Spinelli. 2011. Uma cidade de imagens: Produções e consumos visuais em meios urbanos, Lisboa: Editora Mundos Sociais. 
Cooke, P. e L. Lazzeretti (org.) 2007. Creative cities, cultural clusters and local development. Cheltenham: Edward Elgar.

Costa, P. 2007. A cultura em Lisboa: competitividade e desenvolvimento territorial. Lisboa: Imprensa de Ciências Sociais.

Costa, P. 2012. "Gatekeeping processes, reputation buiding and creative milieus: evidence from case studies in Lisboa, Barcelona and São Paulo”. Pp. 286-306 in Creative industries and innovation in Europe: Concepts, measures and comparatives case studies, edited by L. Lazzeretti. London and New York: Routledge.

Costa, P. (org.) 2013 (forthcoming). Criatividade e Vitalidade Urbana. Lisboa, Barcelona e São Paulo, em publicação.

Costa, P; M. Magalhães, B. Vasconcelos, e G. Sugahara 2008. “On 'Creative Cities' governance models: a comparative approach”. The Service Industries Journal, Vol. 28, n³-4, April-May 2008: 393-413.

Costa, P.; C. Latoeira e R. Lopes. 2010. Apropriação, conflitos de uso e produção do espaço público em 3 bairros criativos: uma abordagem fotográfica ao Bairro Alto, Gracia e Vila Madalena, Dinamia'CET Working Paper, WP 07/10, DINÂMIA-CET, Lisboa.

DiMaggio, P. 1987. "Classification in art”, American Sociological Review, 1987, vol. 52, August: 440-455.

Ferro, L. 2005. “Ao Encontro da Sociologia Visual”. Sociologia - Revista da Faculdade de Letras da Universidade do Porto, nº15: 373-398.

Fortuna, C. (org.) 1997. Cidade, Cultura e Globalização-Ensaios de Sociologia. Oeiras: Celta .

Hospers, G.-J. 2003. “Creative cities: branding places in knowledge economy”. Technology, छ॰ Policy, 16(3): 143-162.

Lynch, K. 1982 (1960). A imagem da cidade. Lisboa: Edições 70.

O'Connor, J., Wynne, D. (ed.). 1996. From the Margins to the Centre: Cultural production and consumption in the post-industrial city. Aldershot: Arena.

Scott, A. J., 2000. The Cultural Economy of Cities. New Delhi / London / Thousand Oaks: Sage.

Silva, S. 2007. "Cultura visual e afirmações identitárias: Novos processos de reconhecimento social", Anais do II Seminário Nacional "Movimentos Sociais, Participação e Democracia”, 25 a 27 de Abril de 2007, UFSC, Florianópolis, Brasil.

Sontag, S. 2008 (1977). On Photography. Londres; Penguin Modern Classics

Zukin, S. 1995. The Cultures of Cities. Cambridge / Oxford: Blackwell.

Liminal SPACES AND URBAN VITALITY: PhOTO-ESSAY ON THE APPROPRIATION OF PUBLIC SPACE IN THREE CREATIVE DISTRICTS

In this photo-essay a personalised approach is made to the appropriation and (re)construction logics of the public space in the context of three creative districts in three cities: Bairro Alto, in Lisbon, Gràcia, in Barcelona and Vila Madalena, in São Paulo. By analysing images collected systematically in these 3 districts, on the basis of a set of pre-established analytical dimensions, the vitality of these spaces is scrutinized, considering their liminal character and the regular use conflicts that are generated in those areas, at the levels of the physical space, the experiences it provides and its symbolic construction. The analysis presented falls within the broader framework of the research developed by the authors under the project CreatCity, which studies 
the roots and forms of governance of "creative dynamics" in various urban contexts in these 3 cities.

Keywords: public space, creativity, urban vitality, visual approach, photography, cultural districts 